\title{
Pedophilia Dalam Komik Toriko Aigan Shoujo Karya Mashin Osakabe
}

\author{
Putu Ella Kumala Sari", Ni Made Andry Anita Dewi, Silvia Damayanti \\ Program Studi Sastra Jepang Fakultas Ilmu Budaya \\ [ellakumala1@gmail.com], [andry_anita@unud.ac.id], [silvia_damayanti@unud.ac.id] \\ Denpasar, Bali, Indonesia \\ *Corresponding Author
}

\begin{abstract}
The title of this research is "Pedophilia in Comic Toriko Aigan Shoujo by Mashin Osakabe". The aims of this research are to describe the characteristic of pedophilia sexual disorders suffered by Shiren, as well as the impact that occurred on Shinju as a victim of pedophilia in Mashin Osakabe's Toriko Aigan Shoujo comic. The theories that have been used are Endaswara's Psychological Psychology (2010), Schmidth's Pedophilia theory (2014) and Danesi's Semiotic theory (2011). Based on the results, Takamagahara Shiren is an adult male who experiences one type of sexual disorder, namely pedophilia. Characteristics of pedophile sexual disorders in Shiren's character based on three dimensions, namely 1). Physiological dimensions are: heterosexual pedophiles and adult men who like a little girl; 2). The psychological dimension is: having a cruel and stubborn character, which can be seen from his behavior, uses various ways to be able to have sex with Shinju. In addition, Shiren's character is also ambitious take revenge on his mother by hurting Shinju; 3). The dimensions of sociology is: Shiren who closes himself to sociaty and dislikes social interaction. The impact experienced by Shinju as a pedophile victims occurred in the physical and psychological. The impact on the physical character of Shinju is the presence of injuries to the body. The impact of pedophilia on the psychology of Shinju are sexual addiction or hypersex, feeling self worthless, feeling ashamed and guilty that she often tries to commit suicide.
\end{abstract}

Keywords: Literary Psychology, Pedophilia, Psychoanalysis

\begin{abstract}
Abstrak
Penelitian ini berjudul "Pedophilia dalam Komik Toriko Aigan Shoujo Karya Mashin Osakabe". Tujuan penelitian ini adalah untuk mendeskripsikan karakteristik gangguan seksual pedophilia yang diidap oleh tokoh Shiren, serta dampak terhadap tokoh Shinju sebagai korban pedophilia dalam komik Toriko Aigan Shoujo karya Mashin Osakabe. Teori yang digunakan adalah teori psikologi sastra oleh Endaswara (2010), teori Pedophilia oleh Schmidt (2014) dan teori Semiotika oleh Danesi (2011). Berdasarkan hasil penelitian, tokoh Takamagahara Shiren merupakan seorang pria dewasa yang mengalami salah satu jenis gangguan seksual yakni pedophilia. Karakteristik gangguan seksual pedophilia pada tokoh Shiren didasarkan pada tiga dimensi yaitu 1) dimensi fisiologis yaitu: heterosexual
\end{abstract}


pedophile dan pria dewasa menyukai anak kecil; 2) dimensi psikologis yaitu: berkarakter kejam serta keras kepala, yang dapat dilihat dari tingkah lakunya yang menggunakan berbagai cara untuk bisa berhubungan seks dengan Shinju. Selain itu, tokoh Shiren juga berambisi untuk membalas dendam pada ibunya dengan menyakiti Shinju; 3) dimensi sosiologi yaitu: tokoh Shiren menutup diri dan tidak menyukai pergaulan sosial. Dampak yang dialami tokoh Shinju sebagai korban pedophilia terjadi pada fisik dan psikologinya. Dampak pada fisik tokoh Shinju yakni adanya luka-luka pada tubuh tokoh Shinju. Dampak pedophilia pada psikologi tokoh Shinju yakni ketagihan seksual atau hypersex, merasa diri tidak berharga serta merasa malu dan bersalah hingga ia sering melakukan percobaan untuk bunuh diri.

\section{Kata kunci: Psikologi Sastra, Pedophilia, Psikoanalisis}

\section{Latar Belakang}

Pelecehan seksual terhadap anak atau pedophilia, telah menjadi fenomena sosial yang berkembang pesat dari waktu ke waktu di masyarakat. Sayangnya, fenomena ini tidak bisa dihindari ataupun dihilangkan. Pedophilia terjadi di seluruh dunia dan terjadi tidak hanya di negaranegara berkembang seperti Indonesia, bahkan terjadi juga di negara-negara maju salah satunya di Jepang. Dengan berkembangnya fenomena di masyarakat dalam menciptakan karya sastra, sudah banyak karya sastra modern yang menampilkan cerita dengan tema kekerasan pada anak khususnya kasus pedophilia, seperti film, novel, cerpen, dan komik. Salah satu komik Jepang yang menampilkan tema pedophilia yakni komik berjudul Toriko Aigan Shoujo karya Mashin Osakabe (2002).

Penelitian ini menggunakan penelitian Damayanti (2013) dalam penelitiannya yang berjudul "Perempuan dalam Puisi Cinta karya Shuntaro Tanikawa dan W.S. Rendra" yang meneliti tentang perempuan imperior atau perempuan yang menjadi korban laki-laki. Penelitian yang dilakukan oleh Damayanti membantu peneliti dalam memahami status perempuan yang imperior dalam masyarakat yang menganut sistem budaya patriarki dan lebih memahami cara menganalisis karakteristik perempuan dalam sebuah karya sastra.

Selain itu, penelitian ini juga menggunakan penelitian Cahyani (2018) yang berjudul "Gender Identity Disorder pada tokoh Yuuta Aoki dalam Komik Bokura no Hentai karya Fumi Fumiko. Penelitian Cahyani memberikan gambaran mengenai cara mendeskripsikan karakteristik gangguan psikologi dalam sebuah karya sastra.

\section{Pokok Permasalahan}

Rumusan masalah dalam penelitian ini adalah sebagai berikut:

a. Bagaimanakah karakteristik seorang pedophile yang terdapat dalam komik Toriko Aigan Shoujo karya Mashin Osakabe?

b. Bagaimanakah dampak perilaku pedophilia terhadap korban dalam komik Toriko Aigan Shoujo karya Mashin Osakabe?

\section{Tujuan Penelitian}

Tujuan dari penelitian ini adalah untuk menganalisis karakteristik seorang pedophile serta dampak yang ditimbulkan pelaku terhadap korban 
dalam komik Toriko Aigan Shoujo karya Mashin Osakabe.

\section{Metode Penelitian}

Penelitian ini dilakukan secara kualitatif dengan metode deskriptif analisis (Ratna, 2004:53). Teori yang digunakan adalah teori Psikologi Sastra yang dikemukakan oleh Endaswara dalam Minderop (2010) sebagai payung utama penelitian. Teori Pedophilia yang dikemukakan oleh Schmidth (2014) untuk menganalisis karakteristik seorang pedophile dan dampak yang ditimbulkan akibat perilaku pedophilia terhadap korban, serta teori Semiotika yang dikemukakan oleh Danesi (2011) untuk menganalisis gambar pada komik.

\section{Hasil dan Pembahasan}

Berikut merupakan penjabaran mengenai hasil analisis pada karakteristik seorang pedophile serta dampak yang terjadi pada korban akibat perilaku pedophilia.

\subsection{Karakteristik Pedophile dalam komik Toriko Aigan Shoujo karya Mashin Osakabe}

Dalam komik Toriko Aigan Shoujo, karakteristik pedophile pada tokoh Shiren dapat dilihat berdasarkan tiga dimensi, yaitu dimensi fisiologis, dimensi psikologis, dan dimensi sosiologis.

\subsubsection{Dimensi Fisiologis}

Dimensi fisiologis merupakan ciriciri fisik tokoh seperti jenis kelamin, usia serta keadaan tubuh untuk menggambarkan karakter tokoh dalam sebuah karya sastra (Satoto, 2014:108). Berdasarkan dimensi fisiologis, karakteristik seorang pedophile dapat dilihat melalui jenis kelamin dan usia dari pelaku dan korban. Berikut merupakan salah satu data mengenai karakteristik seorang pedophile berdasarkan dimensi fisiologis.

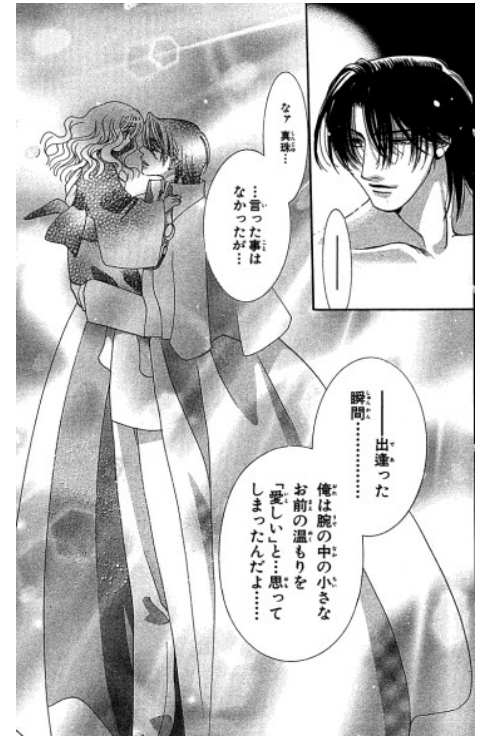

Gambar 1. Perbandingan Postur Tubuh Tokoh Shiren dan Shinju.

(Toriko Aigan Shoujo 1, 2002:76)

Gambar

merupakan penggambaran tubuh Shiren dan Shinju. Seperti yang ada pada gambar tersebut, terlihat tubuh Shiren yang tinggi dan gagah sedang menggendong tubuh kecil Shinju. Dari perbedaan postur tubuh itu, dapat dikatakan perbedaan usia mereka yang terpaut jauh, yakni Shiren yang berusia 24 tahun, sedangkan Shinju yang masih berusia tiga tahun. Oleh sebab itu, dari analisis, tokoh Shiren adalah seorang pedophile karena menyukai anak kecil berusia tiga tahun.

Shiren merupakan seorang pria dewasa yang mengalami gangguan seksual pedophilia dengan jenis heterosexual pedophile, yakni pelaku yang merasa tertarik dengan seorang anak kecil yang jenis kelaminnya berbeda.

\subsubsection{Dimensi Psikologi}

Dimensi psikologis merupakan dimensi penokohan yang meliputi tingkah laku, ambisi, serta karakter seorang tokoh dalam sebuah karya sastra (Satoto, 2014:108). Dalam komik Toriko Aigan Shoujo, karakteristik seorang pedophile yakni Shiren yang dilihat berdasarkan dimensi psikologis yaitu 
tingkah laku Shiren yang ingin mendapatkan tokoh Shinju untuk berhubungan seksual dengan memberikan hal-hal yang disukai korban, dan membujuk korban untuk melakukan hubungan seks. Gangguan seksual yang dialami oleh tokoh Shiren tersebut disebabkan oleh ambisinya untuk membalas dendam pada ibunya karena sudah mencampakkannya ketika ia kecil. Berikut merupakan salah satu data mengenai karakteristik tokoh Shiren sebagai seorang pedophile berdasarkan dimensi psikologis.

$$
\begin{aligned}
& \text { 紫蓮：お前に「背徳」を } \\
& \text { 教えてやる. . } \\
& \text { 真珠：はい. . . とく? } \\
& \text { 紫蓮：お前はただ俺のみに } \\
& \text { 従い、俺だけを感じ } \\
& \text { る。 } \\
& \text { （囚愛玩少女 1、2002:52） }
\end{aligned}
$$

Terjemahan :

Shiren : Aku akan mengajarkanmu moralitas...

Shinju : Moralitas?

Shiren : Kau hanya mengikutiku, yang kau rasakan hanya aku.

Data (1) merupakan percakapan antara Shiren dan Shinju. Shiren yang merupakan seorang bangsawan, tentunya memiliki standar, kualitas serta tata krama yang tinggi, sedangkan Shinju yang hanya seorang budak dan anak yatim piatu, tidak mengetahui tentang hal-hal tersebut. Dengan kondisi seperti itu, Shiren memanfaatkan kondisi Shinju yang masih polos dan lugu untuk melakukan hubungan seksual dengannya. Pada data (1), terdapat kalimat "omae $n i$ [haitoku] wo oshiete yaru..." yang artinya "aku akan mengajarkamu moralitas...", merupakan cara tokoh Shiren untuk membujuk Shinju agar mau mengikuti perkataan dan perintahnya. Setelah Shinju menuruti dan mengikuti perkataan Shiren, dari sanalah ia mulai melakukan kontak seksual seperti mencium bibir dan dada Shinju, yang dapat dilihat pada gambar berikut.

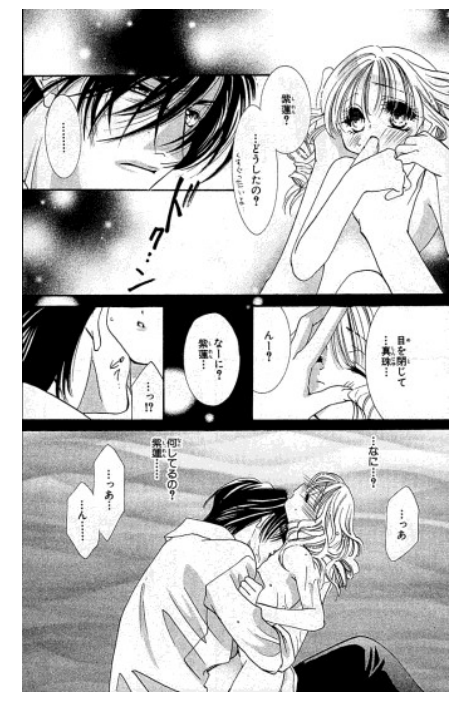

\section{Gambar 2. Tokoh Shiren mulai melampiaskan nafsu seksualnya pada Shinju.}

(Toriko Aigan Shoujo 1, 2002: 53)

Gambar (2) adalah penggambaran Shiren yang mulai melampiaskan nafsu seksualnya pada Shinju. Shiren mengatakan akan mengajarkan tata krama dan moralitas pada Shinju, dengan tujuan agar Shinju mau mengikuti semua perintahnya. Namun, bukannya tata krama yng diajarkan oleh Shiren, ia justru melakukan kontak seksual dengan Shinju, yakni menciumi dada Shinju, seperti yang terlihat pada gambar (2). 
Shinju yang tidak mengerti dengan tindakan Shiren, hanya terdiam dan mengikuti semua arahan Shiren, seperti menutup mata dan hanya merasakan sentuhan Shiren. Hal tersebut merupakan cara yang digunakan oleh Shiren agar bisa melampiaskan nafsu seksualnya pada Shinju, yakni dengan mengatakan akan mengajarkan tata krama serta moralitas pada gadis kecil itu.

\subsubsection{Dimensi Sosiologi}

Dimensi sosiologis merupakan dimensi penokohan yang meliputi ciriciri kehidupan masyarakat seperti interaksi tokoh di lingkungan sekitarnya, serta kehidupan pribadi tokoh (Satoto, 2014:104). Dalam komik Toriko Aigan Shoujo, tokoh Shiren cenderung menutup diri di lingkungan sosialnya dan tidak peduli dengan perkataan orang lain tentang dirinya. Hal tersebut dapat dilihat pada data berikut.

（2）貴族 : 近頃頻繁にお通いにな

る

のね。お目当ての女性

でもおありなのかしら

まさか...

紫蓮：本当に暇潰しです。

こんな私でも世間を知

5

$$
\text { ねばと思っているので }
$$

す

よ。

（囚愛玩少女 5, 2002:6）

Kizoku : Chikagoro hinpan ni okayoi ni naru no ne. $O$ me ate no jousei demo o ari nano kashira...

masaka...

Shiren : Hontou ni himafustushi desu. konna watashi demo seken wo shiraneba to omotte iru no desu yo.

（囚愛玩少女 5, 2002:6）

Terjemahan :

Bangsawan : Akhir akhir ini Anda sering hadir di pesta perjamuan. Apakah untuk bertemu

gadis

yang disukai?

Jangan-jangan...

Shiren : Hanya untuk mengisi waktu luang.

Karena orang seperti saya jarang bergaul.

Data (2) adalah percakapan antara seorang bangsawan yang ditemui oleh Shiren di sebuah pesta. Bangsawan tersebut menyapa Shiren yang jarang terlihat hadir di pesta. Hal tersebut diakui Shiren dengan menyatakan dirinya jarang bergaul, karena ia memang tidak terlalu menyukai pergaulan sosial. Seorang pedophile cenderung menutup diri di lingkungan sekitarnya dan memilih lawan bicaranya untuk berkomunikasi. Sikap Shiren yang jarang menghadiri pesta dan lebih menutup diri tersebut, mencerminkan dirinya yang mengalami gangguan seksual pedophilia. Seperti yang dinyatakan oleh Schimdt (2014), bahwa seorang pedophile lebih memilih untuk menutup diri dan gangguan seksual yang dialaminya tidak ingin diketahui oleh orang lain.

\subsection{Dampak Perilaku Pedophilia Terhadap Korban dalam Komik Toriko Aigan Shoujo karya Mashin Osakabe \\ Dampak dari perilaku pedophilia yang dialami oleh tokoh Shinju terjadi}


pada fisik dan mentalnya. Tokoh Shinju mengalami banyak luka di sekujur tubuhnya dan mengalami beberapa dampak psikologis seperti ketagihan seksual atau hypersex, merasa malu dan bersalah, serta merasa diri tidak berharga, yang menyebabkan tokoh Shinju melakukan percobaan untuk bunuh diri. Berikut merupakan salah satu data mengenai dampak dari perilaku pedophilia yang dialami oleh tokoh Shinju.

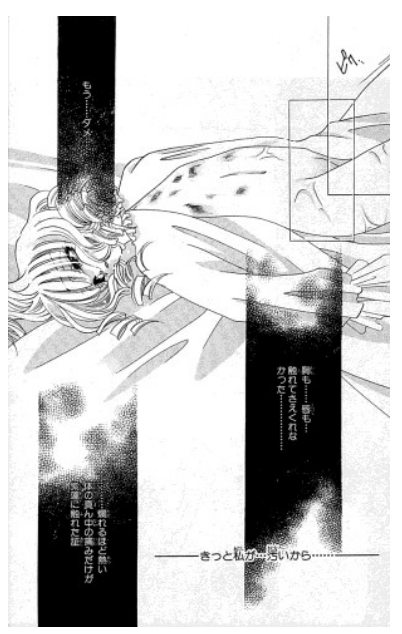

Gambar 3. Penggambaran fisik tokoh Shinju yang penuh dengan luka.

(Toriko Aigan Shoujo 3, 2002:46)

Gambar (3) menunjukkan sekujur tubuh Shinju yang penuh luka karena perlakuan kasar Shiren. Hal tersebut terjadi karena, Shiren yang mengetahui Shinju diperkosa oleh orang tidak dikenal, dan merasa kesal dengan hal tersebut, kemudian menyakiti tubuh Shinju dengan menggigit luka-luka yang ada di tubuh Shinju sebelumnya semakin parah. Pada gambar (3) terlihat tubuh Shinju yang lemas dengan keadaan setengah telanjang dan penuh luka. Pandangan matanya yang kosong menunjukkan jika dirinya lemah tidak berdaya.

(3) 真珠 : 紫蓮、苦し...

苦しい...
紫蓮：なに？真珠？

$$
\begin{aligned}
& \text { なんだ... ? } \\
& \text { もつとゆっくり... }
\end{aligned}
$$

真珠 : あつ ... がう..

ちが.......

ひどくしていい...

（囚愛玩少女 2, 2002:136）

Shinju : Shiren, kurushi... kurushii...

Shiren : Nani? Shinju? Nan da!? Motto yukkuri...

Shinju : Aa... gau ... chiga ...u.. hidokushite ii

(Toriko Aigan Shoujo 2, 2002:136)

Terjemahan :

Shinju : Shiren, sakit... sakit...

Shiren : Apa? Shinju? Ada apa!?

Aku akan pelan-pelan...

Shinju : Bukan... bukan... kau boleh berbuat kasar

Data (3) menunjukkan Shinju yang mengalami ketagihan seksual. Perilaku seksual yang seringkali dialaminya, membuat dirinya tidak mampu untuk mengontrol perilaku seksualnya. Ia menjadi ketagihan untuk berhubungan seksual meskipun usia dan tubuhnya masih belum cukup dewasa untuk melakukan hubungan itu. Bahkan ia memperbolehkan tokoh Shiren untuk berbuat kasar pada dirinya. Ketagihan seksual tersebut merupakan salah satu gangguan seksual yang dialami seorang anak jika ia sudah terlalu sering menerima perilaku pedophilia (Noviana, 2015:20).

\section{Simpulan}

Berdasarkan hasil penelitian, tokoh Takamagahara Shiren merupakan seorang pria dewasa yang mengalami 
salah satu jenis gangguan seksual yakni pedophilia. Karakteristik gangguan seksual pedophilia pada tokoh Shiren berdasarkan tiga dimensi yaitu 1) dimensi fisiologis yaitu: heterosexual pedophile dan pria berusia 24 tahun yang menyukai anak usia delapan tahun; 2) dimensi psikologis yaitu: memiliki karakter kejam serta keras kepala, yang dapat dilihat dari tingkah lakunya yang menggunakan berbagai cara untuk bisa berhubungan seks dengan Shinju. Selain itu, tokoh Shiren juga berambisi untuk memiliki secara utuh tubuh Shinju untuk berhubungan seks; 3) dimensi sosiologi yaitu: tokoh Shiren yang menutup diri dan tidak menyukai pergaulan sosial.

Dampak yang dialami tokoh Shinju sebagai korban pedophilia terjadi pada fisik dan psikologinya. Dampak pada fisik tokoh Shinju yakni adanya luka-luka pada tubuh tokoh Shinju. Dampak pedophilia pada psikologi tokoh Shinju yakni ketagihan seksual atau hypersex, merasa diri tidak berharga serta merasa malu dan bersalah hingga ia sering melakukan percobaan untuk bunuh diri.

\section{Daftar Pustaka}

Cahyani, Ni Made Ariska Dwi. 2018. "Gender Identity Disorder pada Tokoh Yuuta Aoki dalam komik Bokura no Hentai karya Fumi Fumiko" (skripsi). Denpasar: Universitas Udayana.

Damayanti, Silvia. 2013. "Perempuan dalam Puisi Cinta Shuntaro Tanikawa dan W.S. Rendra" (jurnal). Bali: Universitas Udayana.

Danesi, Marcel. 2011. Pesan Tanda Dan Makna. Yogyakarta: Jalasutra.

Endraswara, Suwardi. 2008. Metodologi Penelitian Sastra Yogyakarta: Pustaka Belajar.
Minderop, Albertine. 2010. Psikologi Sastra: karya sastra, metode, teori dan contoh kasus. Jakarta: Yayasan Pustaka Obor Indonesia.

Noviana, Ivo. 2015. Kekerasan Seksual Terhadap Anak: Dampak Dan Penanganannya. Jakarta: Pusat Penelitian dan Pengembangan Kesejahteraan Sosial.

Osakabe, Mashin. 2002. Toriko Aigan Shoujo. Japan: Shogakukan.

Ratna, Nyoman Kutha. 2004. Teori, Metode, dan Teknik Penelitian Sastra. Yogyakarta: Pustaka Belajar.

Satoto, Soediro. 2014. Sastra: Ideologi, Politik, dan Kekuasaan. Surakarta: Muhammadiyah University Press.

Schimdt, dkk. 2014. Abnormal Psychology Elevent Edition. Amerika: Jhon Wiley \& Sons Inc. 